\title{
MR Imaging of Teflon Induced Granuloma as a Cause of Recurrent Tri- geminal Neuralgia Following Microvascular Decompression
}

\section{Soni $\mathbf{N}^{*}$ and Sunil K}

${ }^{1}$ Department of radiodiagnosis, Sanjay Gandhi Post Graduate Institute of Medical Sciences, Lucknow, Uttar pradesh, India

\begin{abstract}
Teflon is an inert material used for microvascular decompression and placed between the trigeminal nerve and offending vessel. Teflon granuloma is considered a less known cause for recurrent facial pain after MVD. Here we report our experience with Teflon ganuloma and its treatment.
\end{abstract}

Keywords: Recurrent trigeminal neuralgia; Microvascular decompression; Teflon granuloma

\section{Description}

A 37 year-old female underwent microvascular decompression (MVD) for right Trigeminal neuralgia TN. She presented with recurrent facial pain after 1.5year of MVD. Teflon was used as an inert material and placed between the nerve and offending vessels for the MVD. She underwent MRI-Head which revealed lobulated hypointense lesion in the right cerebellopontine angle involving cisternal segment of trigeminal nerve (TGN) on FIESTA sequence (Figure 1A). Post contrast enhancement was seen on T1-weighted image (Figure 1B) raising the suspicion for active granulomatous lesion. Blooming was noted on susceptibility image (Figure 1C) which represents either calcification or blood degradation products. No neurovascular contact was found on MR-angio TOF image (Figure 1D). She underwent re-exploration for the complete removal of the granuloma. Histopathological examination of the enhancing mass confirmed the findings of granulomatous inflammation. Post-operative follow-up was uneventful with no neurological deficit.

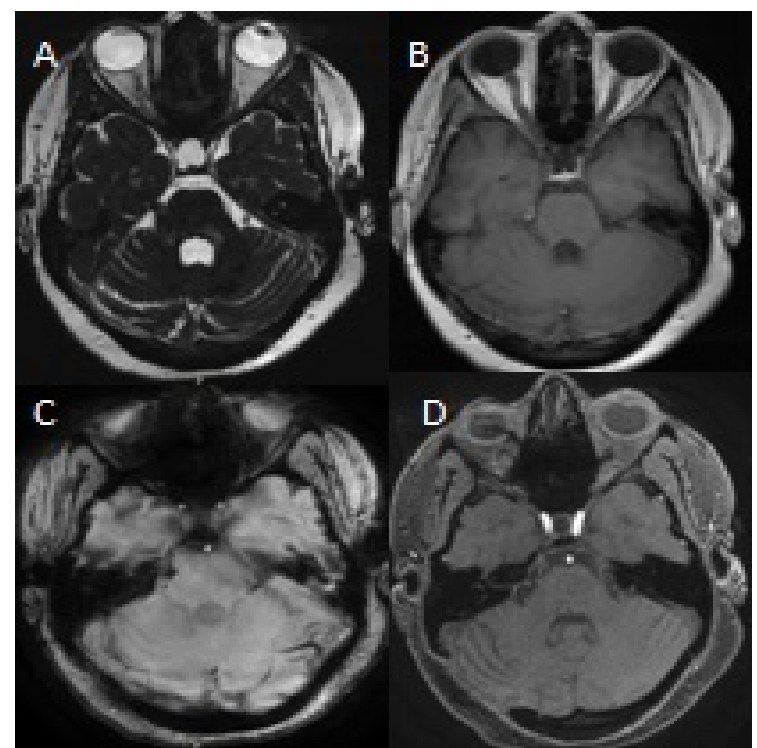

Figure 1: Imaging studies of Teflon granuloma-(A) FIESTA Axial view demonstrates a hypointense lesion in the right cerebello-pontine angle involving the cisternal segment of trigeminal nerve. (B) Post-contrast axial T1weighted MR scan shows gadolineum enhancement at the location of MVD Teflon placement. (C) Susceptibility image reveals blooming within the mass corresponding to focal calcification. (D) MR-angio TOF image demonstrates no neurovascular contact.
Trigeminal neuralgia (TN) is characterised by the recurrent episodic, severe pain in the distribution of trigeminal nerves (TGN). Vascular compression of TGN at its root entry zone (REZ) which was first recognised as a cause of TN by Jannetta in 1967 and found in $80-90 \%$ of patients TN $[1,2]$. Microvascular decompression (MVD) is considered to be the effective and relatively safe surgery in which a piece of polytetrafluoroethylene (PTFE) is usually placed between the trigeminal nerve and the culprit blood vessel. Various explanations have been mentioned for the recurrent TN after microvascular decompression (MVD) such as insufficient decompression, dislocation of the implant to pad the neurovascular contact, or the development of granuloma. Teflon is presumed to be an inert material; however it can induce giant-cell reaction when it comes in contact with dura and tentorium and responsible for recurrent TN. So teflon should be kept completely within the CSF space. Teflon granuloma is less known among neurosurgeons, neurologists, and pain specialists with reported incidence of $1.1-7.3 \%$ by the few studies. Clinically suspicion of Teflon granuloma can be made in patients with development of new facial pain after MVD. MRI and CT imaging further helps in making the diagnosis $[3,4]$. This case highlights the importance of imaging studies in making the early diagnosis of teflon granuloma which is a rare cause for recurrent facial pain after MVD for TN. Re-exploration is a safe and effective surgical approach in the treatment of Teflon induced recurrent TN after failed MVD [5].

\section{References}

1. Jannetta PJ (1967) Arterial compression of the trigeminal nerve at the pons in patients with trigeminal neuralgia. J Neurosurg 26: 159-162.

2. Capelle HH, Brandis A, Tschan CA, Krauss JK (2010) Treatment of recurrent trigeminal neuralgia due to Teflon granuloma. J Headache Pain 11: 339-344.

3. Chen J, Lee S, Lui T, Yeh Y, Chen T, et al. (2000) Teflon granuloma after microvascular decompression for trigeminal neuralgia. Surg Neurol 53: 281-287.

4. Premsagar IC, Moss T, Coakham HB (1997) Teflon-induced granuloma following treatment of trigeminal neuralgia by microvascular decompression. Report of two cases. J Neurosurg 87: 454-457.

*Corresponding author: Neetu Soni, Department of radiodiagnosis, Sanjay Gandhi Post Graduate Institute of Medical Sciences, Raebariely road, P.O. Box: 226014, Lucknow, Uttar pradesh, India, Tel: 915222494567; E-mail: neetu_soni06@yahoo.co.in,drneetusoni98@gmail.com

Received September 19, 2015; Accepted September 22, 2015; Published September 25, 2015

Citation: Soni N, Sunil K (2015) MR Imaging of Teflon Induced Granuloma as a Cause of Recurrent Trigeminal Neuralgia Following Microvascular Decompression. J Neurol Disord S1: i001. doi:10.4172/2329-6895.S1-i001

Copyright: @ 2015 Soni N, et al. This is an open-access article distributed under the terms of the Creative Commons Attribution License, which permits unrestricted use, distribution, and reproduction in any medium, provided the original author and source are credited. 